\title{
Risk factors for the development of restenosis following stent implantation of venous bypass grafts
}

\author{
U E Heidland, M P Heintzen, C J Michel, B E Strauer
}

\begin{abstract}
Objective-To analyse the variables involved in the high restenosis rate following stent implantation in coronary artery bypass grafts.

Design-A retrospective analysis of a consecutive group of patients attending a tertiary centre. Patients-The long term angiographic outcome of 219 stent implantations for individual lesions performed in 191 patients was investigated. Multivariate analysis correlated clinical, procedural, and angiographic variables with the incidence of angiographic restenosis, defined as diameter stenosis $>50 \%$ at follow up.

Results-Angiographic restenosis was observed in 34\% of lesions treated. Multiple logistic regression analysis defined diabetes mellitus (odds ratio 6.91, 95\% confidence interval (CI) 2.43 to 9.69$)$, graft recanalisation $(2.89,95 \%$ CI 1.18 to 6.63$)$, lesion at the aortic anastomosis $(6.98$, $95 \%$ CI 2.77 to 21.31 ), lesion at the coronary anastomosis (3.01, 95\% CI 1.19 to 7.69 ), high diameter stenosis after stent placement $(7.21,95 \%$ CI 2.66 to 16.81$)$, placement of long stents (2.73, 95\% CI 1.09 to 7.39$)$, and implantation of more than one stent $(7.31,95 \%$ CI 2.08 to 19.96) as independent predictors of graft in-stent restenosis.

Conclusions-There appears to be a specific risk factor constellation contributing to the high restenosis rate following stent implantation in venous bypass grafts. Critical consideration of these variables may help identify patients who are poor candidates for stent implantation and who may benefit from a different approach.
\end{abstract}

(Heart 2001;85:312-317)

Keywords: coronary artery bypass graft; stent; restenosis

Owing to the increasing number of patients who have undergone bypass surgery, treatment of obstructive disease in the grafts is an emerging problem. Within a decade following bypass surgery, severe atherosclerotic disease is present in more than half of saphenous vein bypass grafts. ${ }^{1-5}$ Choosing the right treatment for patients with obstructive disease of coronary artery bypass grafts is a challenge for the future. Repeated grafting is complicated by increased morbidity and mortality and has a worse clinical outcome than a first bypass operation. ${ }^{67}$ Balloon angioplasty of stenosed venous grafts is associated with a high incidence of periprocedural complications and high restenosis rates compared with balloon angioplasty of native coronary arteries. ${ }^{8-13}$ Randomised trials comparing intracoronary stent implantation with balloon angioplasty for de novo discrete lesions of native coronary arteries have shown better long term results after stent implantation owing to a lower restenosis rate. ${ }^{14}{ }^{15}$ In addition, stent implantation has proved its efficacy in interventions with a high risk of restenosis such as recanalisation of chronically occluded coronary arteries, ${ }^{16}$ the treatment of patients with acute myocardial infarction, ${ }^{17}$ and in some studies the treatment of patients with diabetes mellitus. ${ }^{18}$

The role of coronary stent placement in the treatment of stenosed coronary artery bypass grafts needs further clarification. Early observational reports suggested better long term results with stent placement in obstructed cor- onary bypass grafts compared with percutaneous transluminal coronary angioplasty (PTCA). ${ }^{19-26}$ However the SAVED (saphenous vein de novo) study ${ }^{27}$ was unable to confirm better long term results after stent implantation of obstructed coronary bypass grafts than after balloon angioplasty. In this latter prospectively randomised trial, stenting resulted in a larger gain in minimum luminal diameter and a reduction in cardiac events during follow up but failed to decrease the rate of angiographic restenosis. Thus there may be a specific risk factor constellation after stent implantation of stenosed venous bypass grafts leading to increased restenosis rates.

Various predictors of restenosis following stent implantation of native coronary arteries have been established, including implantation of multiple stents, stenosis length, and small vessel diameter. ${ }^{28}$ This is the first investigation analysing the contribution of procedural, angiographic, and clinical variables to the process of restenosis following stent implantation of obstructed coronary vein grafts.

\section{Methods}

PATIENT SELECTION

In this study we analysed long term results of consecutive patients receiving primary successful stent implantation for obstructive disease of coronary artery bypass grafts between January 1996 and December 1998 in a single centre. During this period, 239 stent implantations of stenosed coronary arteries were performed in 
209 patients. Long term follow up was not available in four patients because they refused to have follow up angiography. These four patients received implantation of a single stent in the setting of stable angina pectoris for lesions located in the proximal or middle third of a focally diseased vein graft. In 14 patients stent implantation was followed by a total of 26 complications, as follows: acute myocardial infarction $(n=12)$, repeat revascularisation of the target vessel during the hospital stay $(n=10)$, repeat bypass operation $(n=2)$, and death $(n=2)$. In this group of 14 patients, 10 were treated for an acute coronary syndrome. In eight of these, recanalisation of a complete occlusion was required, so there was a lower mean minimum lumen diameter and a higher degree of diameter stenosis before the intervention in this subgroup of patients. There was also a high prevalence of diabetes mellitus $(n=7)$. Long term follow up was available in six of the 14 patients with complications, of whom four presented with restenosis. This means that 20 stent implantations performed in 18 individual patients were not included in the long term follow up. Thus long term follow up was available in 191 patients receiving 219 primary successful stent implantations for individual lesions (94.8\% of all stents).

The procedure was considered successful when residual stenosis following stent implantation of a stenosis of $\geqslant 50 \%$ was less than $40 \%$ on quantitative coronary angiography, without major cardiovascular complications (myocardial infarction, need for coronary artery bypass grafting, repeat revascularisation of the target vessel, death) during the hospital period. Exclusion criteria were contraindications to treatment with aspirin and ticlopidine, and outflow obstruction of the graft because of poor run off in the recipient native vessel. None of the patients included received stent implantation because of unsuccessful PTCA. Angiographic long term follow up was done in all patients at a mean (SD) of 6.1 (2.2) months after stent implantation. Unscheduled angiography was allowed on a clinical basis (for example, symptomatic angina before the scheduled six month follow up). However, if restenosis was not observed during unscheduled angiography, repeat angiography was performed six months after stent implantation. Owing to the expectedly high restenosis rates, routine angiographic follow up six months after stent implantation was considered normal clinical practice in this subset of patients. This practice was approved by the local ethics committee.

STENT IMPLANTATION

All lesions received predilatation by conventional PTCA. All patients were treated with standard intravenous heparin $(10000 \mathrm{U})$, aspirin $(500 \mathrm{mg})$, and intracoronary isosorbide dinitrate $(0.3-0.6 \mathrm{mg})$. Heparin was titrated to maintain an activated clotting time of $>300$ seconds. The following stent types were used: ACS Multi Link ( $n=172)$; AVE $(n=15)$; Nir $(\mathrm{n}=12)$; Bard XT $(\mathrm{n}=8)$, Palmaz-Schatz $(n=6)$; and Wiktor $(n=6)$. There was no predefined stent implantation protocol using on-line quantitative coronary angiography. Medical treatment following stent implantation consisted of aspirin (100 mg) and ticlopidine (250 mg twice a day). Aspirin was started at least 24 hours before stent implantation and was continued. Treatment with ticlopidine was initiated immediately after stent placement and was continued for six weeks. Glycoprotein (GP) IIb/IIIa receptor antagonists were used in 31 stent implantations (abciximab in 17, tirofiban in 14). Indications for the application of GP IIb/IIIa receptor antagonists included intravascular thrombus formation and stent implantation in the setting of acute coronary syndromes.

ANGIOGRAPHIC ANALYSIS AND DEFINITIONS Quantitative coronary angiography of the target lesion was performed with the help of an automatic edge detection system, referring to the known diameter of the guiding catheter performed on selected magnified cineframes (Cardio 500, Kontron, Neufahrn, Germany). All cineangiograms were reviewed by a single experienced observer. Assessment of the degree of stenosis was performed in the angiographic view displaying the most severe stenosis. In cases of sequential stent implantations in different stenosed parts of the graft all lesions were analysed. Stenosis degree (\%), minimum lumen diameter $(\mathrm{mm})$, vessel diameter $(\mathrm{mm})$, and stenosis length $(\mathrm{mm})$ were assessed by quantitative coronary angiography. Vessel diameter was measured in the direct vicinity of the stenosed graft by averaging the normal appearing segments proximal to and distal to the lesion. Analyses were performed before angioplasty, immediately after angioplasty, and at the six month follow up, using identical projections after intracoronary nitrate injection. Primary successful PTCA was defined as residual stenosis of $<40 \%$ after angioplasty of a stenosis of $>50 \%$. Angiographic restenosis was defined as diameter stenosis $>50 \%$ within the stent or at the edges of the stent at follow up.

\section{CLINICAL, PROCEDURAL, AND ANGIOGRAPHIC} PREDICTORS

Data on restenotic lesions were compared with data on lesions with stenosis of $<50 \%$ at follow up. Data on patients presenting with completely occluded stents at follow up were also included in the analysis. In order to identify risk factors associated with restenosis following stent implantation of stenosed venous bypass grafts, the contribution of various clinical, procedural, and angiographic variables was assessed.

\section{Clinical variables}

Clinical variables consisted of age, sex, clinical presentation (stable angina, acute coronary syndrome (unstable angina defined as class III, class B and C according to Braunwald ${ }^{29}$ ), acute myocardial infarction), and cardiovascular risk factors. Risk factors included arterial hypertension (defined as a blood pressure of $>160 / 95 \mathrm{~mm} \mathrm{Hg}$ on three consecutive 
measurements), diabetes mellitus (patients on oral antidiabetic treatment, those with insulin dependent diabetes mellitus, and those with a blood glucose of $>200 \mathrm{mg} / \mathrm{dl}$ two hours after oral intake of $75 \mathrm{~g}$ glucose), hypercholesterolaemia (defined as a total plasma cholesterol concentration of $>5.2 \mathrm{mmol} / 1(200 \mathrm{mg} /$ dl)), and a family history of coronary artery disease.

Procedural variables

Procedural variables included recipient native vessel, graft recanalisation for complete obstruction, graft age, previous stent implantation of the graft at a different location, lesion $>45 \%$ at a bend point, stenosis eccentricity (assessed by quantitative angiography), stenosis location (aortic anastomosis, proximal third, middle third, distal third, coronary anastomosis), baseline state of the vein graft and the recipient vessel (focally or diffusely diseased), and contractility of the myocardium supplied (normokinetic $v$ reduced contractility).

\section{Angiographic variables}

Angiographic variables were minimum lumen diameter before and after stent implantation, acute gain (minimum lumen diameter after stent implantation minus the diameter before stent implantation), diameter stenosis before and after stent implantation, reference diameter, lesion length, stent length, multiple stent implantation (implantation of more than one stent in the same graft during the same procedure), and inflation pressure (atm).

In the case of implantation of more than one stent, clinical determinants were analysed in each individual patient, while procedural and angiographic variables were assessed for each stent implantation.

STATISTICAL ANALYSIS

All data are presented as mean (SD). Significance was accepted with probability values of $\mathrm{p}<0.05$. Discrete variables were compared as rates, and comparisons were made using $\chi^{2}$ analysis. However, when the expected value of a cell was less than 5, Fisher's exact test was used. Continuous variables were analysed using two tailed $t$ tests for independent samples. Logistic regression analysis was performed to determine associations between clinical, procedural, and angiographic predictors and the incidence of angiographic restenosis, using only those variables that were significant at the $p<0.01$ level in the univariate analysis. These data are presented as odds ratios (OR) and 95\% confidence intervals (CI). Continuous variables were dichotomised by cut off points derived by dividing the data into two groups, each containing approximately $50 \%$ of the population. Statistical analysis was performed using PC-SAS software, version 6.10 .

\section{Results}

PATIENTS

Long term follow up was obtained in 191 patients receiving stent implantation for 219 lesions. The major clinical and procedural
Table 1 Patient baseline clinical characteristics $(n=191)$

\begin{tabular}{lr}
\hline Age (years) (mean (SD)) & $68(6)$ \\
Female & $19(10 \%)$ \\
Diabetes mellitus & $46(24 \%)$ \\
Hypertension & $143(75 \%)$ \\
Hypercholesterolaemia & $107(56 \%)$ \\
Family history of CAD & $88(46 \%)$ \\
Acute coronary syndrome & $48(25 \%)$ \\
\hline
\end{tabular}

Values are $\mathrm{n}(\%)$ unless specified.

$\mathrm{CAD}$, coronary artery disease.

Table 2 Baseline procedural lesion characteristics $(n=219)$

\begin{tabular}{lr}
\hline Recipient native vessel & \\
LAD & $105(48 \%)$ \\
LCx & $55(25 \%)$ \\
RCA & $59(27 \%)$ \\
Graft recanalisation & $29(13 \%)$ \\
Graft age (years) (mean (SD)) & $12(3)$ \\
Previous stent implantation of graft & $39(18 \%)$ \\
Bend location (> 45\%) & $26(12 \%)$ \\
Eccentric stenosis & $92(42 \%)$ \\
Location of target lesion & $31(14 \%)$ \\
Aortic anastomosis & $61(28 \%)$ \\
Proximal third & $57(26 \%)$ \\
Middle third & $50(23 \%)$ \\
Distal third & $20(9 \%)$ \\
Coronary anastomosis &
\end{tabular}

Data are $\mathrm{n}(\%)$ unless specified.

LAD, left anterior descending coronary artery; LCx, left circumflex coronary artery; RCA, right coronary artery.

Table 3 Complete quantitative coronary angiography $(n=219)$

\begin{tabular}{ll}
\hline $\begin{array}{l}\text { Minimum lumen diameter (mm) } \\
\text { Before }\end{array}$ & $0.94(0.48)$ \\
After & $2.84(0.50)$ \\
Follow up & $1.84(0.89)$ \\
Reference diameter (mm) & $3.23(0.57)$ \\
Before & $3.24(0.61)$ \\
After & $3.22(0.54)$ \\
Follow up & $71(14)$ \\
Diameter stenosis (\%) & $12(9)$ \\
Before & $43(26)$ \\
After & $1.89(0.56)$ \\
Follow up & $0.99(0.70)$ \\
Acute gain (mm) & $0.90(0.69)$ \\
Late loss (mm) & $7.5(3.2)$ \\
Net gain (mm) & $75(34 \%)$ \\
Lesion length (mm) & $9(4 \%)$ \\
Restenosis & \\
Reocclusion & \\
\hline
\end{tabular}

Data are mean (SD) or $\mathrm{n}(\%)$.

characteristics are summarised in tables 1 and 2. Ten per cent of patients were female. Diabetes mellitus was present in $24 \%$ of the patients. One quarter of the patients had stent implantation in the setting of an acute coronary syndrome. The left anterior descending coronary artery was the recipient vessel in almost half the lesions. Graft recanalisation for graft obstruction was performed in $13 \%$ of cases. The mean graft age was 12 years. In $23 \%$ of the lesions, the location was at the aortic or coronary anastomosis of the graft. Implantation of a single stent was performed in $85 \%$ of the patients.

Results of quantitative coronary angiography are shown in table 3. Stent implantation reduced diameter stenosis (mean (SD)) from $71(14) \%$ to $12(9) \%$, achieving an acute gain of almost $1.9 \mathrm{~mm}$. At follow up a late loss of almost $1 \mathrm{~mm}$ had increased the mean diameter stenosis to $43(26) \%$, resulting in a net gain of $0.9 \mathrm{~mm}$. Angiographic restenosis was observed in $34 \%$ of lesions treated by stent implantation, while reocclusion occurred in $4 \%$. 
Table 4 Univariate analysis of predictors of restenosis: clinical variables

\begin{tabular}{|c|c|c|}
\hline & $\begin{array}{l}\text { Restenosis } \\
\text { rate (\%) }\end{array}$ & is $p$ Value \\
\hline \multicolumn{3}{|l|}{ Age (years) } \\
\hline$<68(\mathrm{n}=104)$ & 27 & \\
\hline$>68(\mathrm{n}=115)$ & 40 & 0.07 \\
\hline \multicolumn{3}{|l|}{ Sex } \\
\hline Male $(n=200)$ & 35 & 0.78 \\
\hline Female $(n=19)$ & 30 & \\
\hline \multicolumn{3}{|l|}{ Diabetes mellitus } \\
\hline Present $(n=53)$ & 61 & $<0.01$ \\
\hline Not present $(n=166)$ & 24 & \\
\hline \multicolumn{3}{|l|}{ Hypertension } \\
\hline Present $(n=161)$ & 31 & \\
\hline Not present $(n=58)$ & 41 & 0.28 \\
\hline \multicolumn{3}{|l|}{ Hypercholesterolaemia } \\
\hline Present $(n=123)$ & 36 & 0.61 \\
\hline Not present $(n=96)$ & 32 & \\
\hline \multicolumn{3}{|l|}{ Family history of coronary artery disease } \\
\hline Present $(n=101)$ & 31 & \\
\hline Not present $(n=118)$ & 37 & 0.64 \\
\hline \multicolumn{3}{|l|}{ Clinical presentation } \\
\hline Stable angina $(n=172)$ & 29 & \\
\hline Acute coronary syndrome $(n=47)$ & 50 & 0.02 \\
\hline \multicolumn{3}{|l|}{ State of graft/vessel } \\
\hline Focally diseased $(n=78)$ & 24 & \\
\hline Diffusely diseased $(n=141)$ & 40 & 0.03 \\
\hline \multicolumn{3}{|l|}{ Myocardial contractility } \\
\hline Normokinetic $(n=48)$ & 29 & \\
\hline Reduced contractility $(n=171)$ & 36 & 0.40 \\
\hline \multicolumn{3}{|c|}{$\begin{array}{l}\text { Table } 5 \text { Univariate analysis of predictors of restenosis: } \\
\text { procedural variables }\end{array}$} \\
\hline & $\begin{array}{l}\text { Restenosis } \\
\text { rate }(\%)\end{array}$ & $p$ Value \\
\hline \multicolumn{3}{|l|}{ Recipient native vessel } \\
\hline $\mathrm{LAD}(\mathrm{n}=105)$ & 35 & 0.88 \\
\hline $\mathrm{LCx}(\mathrm{n}=55)$ & 30 & \\
\hline $\mathrm{RCA}(\mathrm{n}=59)$ & 35 & \\
\hline \multicolumn{3}{|l|}{ Graft recanalisation } \\
\hline Yes $(n=29)$ & 66 & $<0.01$ \\
\hline No $(n=190)$ & 30 & \\
\hline \multicolumn{3}{|l|}{ Graft age (years) } \\
\hline$<12(\mathrm{n}=96)$ & 35 & 0.88 \\
\hline$>12(\mathrm{n}=123)$ & 34 & \\
\hline \multicolumn{3}{|l|}{ Previous stent implantation } \\
\hline Yes $(n=42)$ & 51 & 0.04 \\
\hline No $(n=177)$ & 31 & \\
\hline \multicolumn{3}{|l|}{ Bend location } \\
\hline Yes $(n=26)$ & 29 & \\
\hline No $(n=193)$ & 35 & 0.79 \\
\hline \multicolumn{3}{|l|}{ Eccentric stenosis } \\
\hline Yes $(n=92)$ & 36 & 0.87 \\
\hline No $(n=127)$ & 33 & \\
\hline \multicolumn{3}{|l|}{ Localisation of target lesion } \\
\hline Aortic anastomosis $(n=31)$ & 68 & $<0.01$ \\
\hline Proximal third $(n=61)$ & 24 & \\
\hline Middle third $(\mathrm{n}=57)$ & 24 & \\
\hline Distal third $(n=50)$ & 22 & \\
\hline Coronary anastomosis $(n=20)$ & 68 & $<0.01$ \\
\hline
\end{tabular}

PREDICTORS OF RESTENOSIS

Univariate analysis of clinical, procedural, and angiographic variables is summarised in tables 4,5 , and 6 . The only cardiovascular risk factor that was associated with an increased rate of in-stent restenosis was diabetes mellitus. Restenosis rate in the presence of diabetes mellitus averaged $61 \%$, compared with $24 \%$ in nondiabetic patients. Furthermore, lesions treated in the setting of acute coronary syndrome showed a significantly increased restenosis rate of $50 \%$, compared with $29 \%$ observed in patients with stable angina.

With respect to procedural variables, stent implantation of lesions localised at the aortic and coronary anastomosis was followed by a greatly increased restenosis rate of $68 \%$. Stent implantation of lesions localised in the proximal, middle, and distal third was complicated by restenosis in only $23 \%$. Graft recanalisation
Table 6 Univariate analysis of predictors of restenosis: angiographic variables

\begin{tabular}{|c|c|c|}
\hline & $\begin{array}{l}\text { Restenosis } \\
\text { rate }(\%)\end{array}$ & $p$ Value \\
\hline \multicolumn{3}{|c|}{ Minimum lumen diameter before (mm) } \\
\hline$<0.95(\mathrm{n}=101)$ & 49 & \multirow[t]{2}{*}{$<0.01$} \\
\hline$>0.95(n=118)$ & 22 & \\
\hline \multicolumn{3}{|c|}{ Minimum lumen diameter after (mm) } \\
\hline$<2.85(\mathrm{n}=113)$ & 56 & \multirow[t]{2}{*}{$<0.01$} \\
\hline$>2.85(\mathrm{n}=106)$ & 12 & \\
\hline \multicolumn{3}{|l|}{ Acute gain $(\mathrm{mm})$} \\
\hline$<1.85(\mathrm{n}=113)$ & 38 & \multirow[t]{2}{*}{0.43} \\
\hline$>1.85(\mathrm{n}=106)$ & 32 & \\
\hline \multicolumn{3}{|c|}{ Diameter stenosis before (\%) } \\
\hline$<70(\mathrm{n}=120)$ & 21 & \multirow[b]{2}{*}{$<0.01$} \\
\hline$>70(\mathrm{n}=99)$ & 53 & \\
\hline \multicolumn{3}{|c|}{ Diameter stenosis after (\%) } \\
\hline$<12(\mathrm{n}=108)$ & 9 & \multirow[b]{2}{*}{$<0.01$} \\
\hline$>12(\mathrm{n}=111)$ & 58 & \\
\hline \multicolumn{3}{|c|}{ Reference diameter (mm) } \\
\hline$<3.2(\mathrm{n}=119)$ & 36 & \multirow[t]{2}{*}{0.44} \\
\hline$>3.2(\mathrm{n}=100)$ & 32 & \\
\hline \multicolumn{3}{|l|}{ Lesion length (mm) } \\
\hline$<7(\mathrm{n}=91)$ & 28 & \multirow[b]{2}{*}{0.17} \\
\hline$>7(\mathrm{n}=128)$ & 38 & \\
\hline \multicolumn{3}{|l|}{ Stent length (mm) } \\
\hline$<15(\mathrm{n}=111)$ & 24 & \multirow{2}{*}{$<0.01$} \\
\hline$>15(\mathrm{n}=108)$ & 44 & \\
\hline \multicolumn{3}{|l|}{ Number of stents } \\
\hline $1(n=163)$ & 29 & \multirow[b]{2}{*}{$<0.01$} \\
\hline $2(n=28)$ & 70 & \\
\hline \multicolumn{3}{|c|}{ Inflation pressure (atm) } \\
\hline$<14(\mathrm{n}=102)$ & 39 & \multirow[t]{2}{*}{0.19} \\
\hline$>14(\mathrm{n}=117)$ & 30 & \\
\hline
\end{tabular}

performed for complete obstruction was also associated with a significantly increased restenosis rate $(66 \%)$. Previous stent implantation of the graft at a different target lesion appeared to contribute to increased restenosis rates but just failed to reach significance. Further procedural variables, including graft age and lesion related characteristics such as stenosis eccentricity and bend location, were not associated with increased rates of restenosis. Diffuse disease of the graft and the recipient vessel was significantly correlated with the incidence of restenosis, but the contractile state of the myocardium supplied had no apparent impact on the restenosis rate.

As expected, minimum lumen diameter before and after stent placement, as well as diameter stenosis before and after the procedure, were strongly correlated with recurrent restenosis. However, acute gain, reference diameter, and stenosis length did not appear to influence the rate of angiographic restenosis. Placement of more than one stent during the procedure was linked to increased restenosis, and implantation of a stent with a length of more than $15 \mathrm{~mm}$ was a significant univariate predictor of restenosis. There was a trend towards higher restenosis rates following stent implantation with comparatively low inflation pressure, but this failed to reach significance.

The results obtained by multivariate analysis are summarised in table 7 . Multiple logistic regression analysis identified diabetes mellitus, recanalisation of a completely occluded graft, location of the target lesion at the coronary and aortic anastomosis, high residual stenosis after stent implantation, placement of long stents, and implantation of more than one stent during the intervention as independent predictors of in-stent restenosis of the graft. On analysing the odds ratios, placement of more than one stent and high residual stenosis after stent 
Table 7 Multiple logistic regression analysis of independent predictors of in-stent restenosis

\begin{tabular}{lcl}
\hline Independent predictor & $p$ Value & OR (95\% CI) \\
\hline Diabetes mellitus & $<0.001$ & $6.91(2.43$ to 9.69$)$ \\
Graft recanalisation & 0.03 & $2.89(1.18$ to 6.63$)$ \\
Aortic anastomosis & $<0.001$ & $6.98(2.77$ to 21.31$)$ \\
Coronary anastomosis & 0.02 & $3.01(1.19$ to 7.69$)$ \\
Diameter stenosis after & & \\
$\quad$ stent placement & $<0.001$ & $7.21(2.66$ to 16.81$)$ \\
Stent length & 0.03 & $2.73(1.09$ to 7.39$)$ \\
Number of stents & 0.002 & $7.31(2.08$ to 19.96$)$ \\
\hline
\end{tabular}

$\mathrm{OR}$, odds ratio; $\mathrm{CI}$, confidence interval.

placement were the strongest predictors of in-stent restenosis.

\section{Discussion}

Our study reports a restenosis rate of $34 \%$ following stent implantation of stenosed venous bypass grafts, which is acceptable but still exceeds the restenosis rates observed after stent implantation of native coronary arteries. Multivariate analysis identified various predictors which contribute to the excess restenosis rate after stent implantation in stenosed venous grafts.

CLINICAL PREDICTORS

The presence of diabetes mellitus represented the only cardiovascular risk factor that was predictive of in-stent restenosis. Restenosis rate of diabetic patients in this study was $61 \%$, probably reflecting increased neointimal hyperplasia because of the stimulatory effects of growth factors. There are conflicting data on the effect of diabetes on restenosis after coronary stent implantation. Some studies ${ }^{18}{ }^{28}$ have shown comparable long term results in diabetic and non-diabetic patients. However, Elezi and colleagues found that the presence of diabetes mellitus was an independent predictor of stent restenosis, increasing the incidence of restenosis from $28 \%$ in non-diabetic patients to $37 \%$ in diabetic patients, ${ }^{30}$ though this is still far below the restenosis rate in diabetic patients receiving stent implantation in venous bypass grafts as documented in our study. Our findings are in accordance with the data reported by Carrozza and colleagues, ${ }^{31}$ who found very high restenosis rates following stent implantation in diabetic patients. In that study most of the patients were treated for stenosed venous bypass grafts. Thus stent implantation of venous bypass grafts in diabetic patients is complicated by an excess restenosis rate, and this seems even to exceed the restenosis occurring in diabetic patients given stent implants in native coronary arteries. Future studies will need to analyse the extent to which more rigorous diabetes control and platelet inhibition may improve the angiographic outcome in diabetic patients.

PROCEDURAL PREDICTORS

Stent implantation has become established as the preferred treatment option in patients requiring recanalisation of completely occluded coronary arteries. In this specific setting very low restenosis rates of $32 \%$ have been reported in the GISSOC (gruppo Italiano di studio sullo stent nelle occlusioni coronariche) trial following primary successful recanalisation. ${ }^{16}$ Our study showed a restenosis rate of $66 \%$ following stent implantation of completely occluded vein grafts, indicating a lack of efficacy of coronary stent implantation in preventing restenosis, and identifying graft recanalisation as an independent predictor of in-stent restenosis. The reason why recanalisation of coronary artery bypass grafts is complicated by higher restenosis rates compared with occluded native coronary arteries remains unclear.

Stenosis location was identified as an important independent predictor of long term success following stent implantation of stenosed venous bypass grafts. Our data showed low restenosis rates of $23 \%$ following stent implantation in the proximal, middle, and distal third of the graft, as compared with a rate of $68 \%$ after implantation in the aortic or coronary anastomoses. One possible explanation for the poor long term results following stent implantation in the coronary anastomosis may be the discrepancy in vessel size between the distal vein graft and the recipient native vessel, which may complicate the implantation of a stent of suitable size. The high restenosis rate following stent implantation of the aortic anastomosis may be caused by an increased in-stent neointimal hyperplastic response, as already documented in native coronary arteries. ${ }^{32}$

\section{ANGIOGRAPHIC PREDICTORS}

Placement of more than one stent ${ }^{28}$ and implantation of long stents ${ }^{33}$ have been defined as predictors of restenosis following stent implantation in native coronary arteries. A possible explanation for these findings refers to increased neointimal proliferation produced by the implantation of multiple or long stents. Our investigation also identified these variables as independent risk factors for graft restenosis, indicating the central role of neointimal proliferation in the pathogenesis of in-stent restenosis of venous bypass grafts as well. However, implantation of long and multiple stents most probably reflects the state of disease in the graft and raises doubt over the suitability of stent implantation in the setting of diffusely diseased grafts.

Stent implantation of small native coronary arteries is complicated by high restenosis rates, ${ }^{34}$ though the reasons for the poor long term results following stent implantation in small coronary arteries remain unclear. In contrast to these findings, we were unable to show a significant impact of small reference diameter on the incidence of restenosis. One possible explanation for the different impact of vessel size on restenosis rates of native coronary arteries and vein grafts may be the comparatively large reference diameter of the coronary artery bypass grafts assessed in our investigation (more than $3.2 \mathrm{~mm}$ ).

\section{LIMITATIONS OF THE STUDY}

The main limitation of our study is its retrospective nature. In this context a selection bias is unavoidable. However, our study involved a consecutive series of stent implanta- 
tions including $91.6 \%$ of all procedures that were performed during the time concerned, indicating that the procedures analysed in this investigation are representative.

One major limitation of our investigation is the comparatively small number of lesions treated. Investigation of larger patient cohorts may identify further predictors of in-stent restenosis of venous bypass grafts which could not be defined in our present study.

The results of our investigation support the concept of a specific restenosis mechanism following stent implantation in stenosed venous bypass grafts, with various different risk factors. However, further investigation using intravascular ultrasound may be helpful in exploring the mechanism of restenosis underlying stent implantation in venous bypass grafts. Intravascular ultrasound can analyse different lesional characteristics, allowing the quantification of their contribution to the process of in-stent graft restenosis.

\section{CONCLUSIONS}

Our data support the hypothesis of a specific risk factor constellation contributing to restenosis following stent implantation in stenosed venous bypass grafts and explaining the comparatively high rates of angiographic restenosis. Recanalisation of completely occluded vein grafts, stenosis localisation, and-not documented by all studies-the presence of diabetes mellitus were associated with poor long term results, raising doubts over the suitability of stent implantation in these specific settings. Some of the strongest predictors of stent restenosis-including diabetes mellitus, stenosis location, and complete graft occlusion-are unfortunately not correctable. However, it is conceivable that more rigorous diabetes control and platelet inhibition may help to improve angiographic long term follow up in patients with diabetes. Critical consideration of the risk factors identified may help to identify patients who are poor candidates for stent implantation in venous bypass grafts and who could benefit from different forms of treatment, including a second bypass operation or the implantation of stent grafts. However, further investigation is required to corroborate our initial results.

1 Bourassa MG, Enjalbert M, Campeau L, et al. Progression of atherosclerosis in coronary arteries and bypass grafts: ten years later. $A m$ F Cardiol 1984;53:102-7C.

2 Bourassa MG, Fisher LD, Campeau L, et al. Long-term fate of bypass grafts: the coronary artery surgery study (CASS) and Montreal Heart Institute experiences. Circulation 1985;72:V-71-8.

3 Fitzgibbon GM, Leach AJ, Kafka HP, et al. Coronary bypass graft fate: long-term angiographic study. $f \mathrm{Am}$ Coll Cardiol 1991;17:1075-80.

4 Hamby RI, Aintablian A, Handler M, et al. Aortocoronary saphenous vein bypass grafts: long-term patency, morphology and blood flow in patients with patent grafts early after surgery. Circulation 1979;60:901-9.

5 Lawrie GM, Lie JT, Morris GC, et al. Vein graft patency and intimal proliferation after aortocornary bypass: early and intimal proliferation after aortocornary bypass: early and long term $856-62$.

6 Cameron A, Kemp HG, Green GE. Reoperation for coronary artery disease: 18 years of clinical follow-up. Circulation 1988; 78:I-158-62.

7 Laird-Meeyer K, van Domburg R, van den Brand MJ, et al. Incidence, risk and outcome of reintervention after aortocoronary bypass surgery. Br Heart f 1987;57:427-35.
8 De Feyter PJ, van Suylen RJ, de Jaegere PPT, et al. Balloon angioplasty for the treatment of lesions in saphenous vein bypass grafts. F Am Coll Cardiol 1993;21:1539-49.

9 Douglas JS, Gruentzig AR, King SB, et al. Percutaneous transluminal coronary angioplasty in patients with prior coronary bypass surgery. F Am Coll Cardiol 1982;2:745-54.

10 Meester BJ, Samson M, Suryapranata H, et al. Long-term follow-up after attempted angioplasty of saphenous vein grafts: the Thoraxcenter experience 1981-1988. Eur Heart f 1991;12:648-53.

11 Platko WP, Hollman J, Whitlow PL, et al. Percutaneous transluminal angioplasty of saphenous vein graft stenosis: long term follow up. $\mathcal{F}$ Am Coll Cardiol 1989;14:1645-50.

12 Reeves F, Bonan R, Cote G, et al. Long-term angiographic follow-up after angioplasty of venous coronary bypass grafts. Am Heart f 1991;122:620-7.

13 Heidland UE, Michel CJ, Heintzen MP, et al. Restenose nach PTCA-Pathophysiologische Grundlagen und Möglichkeiten der pharmakologischen und katheterinterventionellen Prävention. Dtsch Med Wochenschr 1998;123: $840-6$.

14 Fischman DL, Leon MB, Baim DS, for the STRESS Investigators. A randomized comparison of coronary-stent placement and balloon angioplasty in the treatment of coronary artery disease. $N$ Engl f Med 1994;331:496-501.

15 Serruys PW, de Jaegere P, Kiemeneij F, et al, for the Benestent Study Group. A comparison of balloon-expandablestent implantation with balloon angioplasty in patients with coronary artery disease. N Engl f Med 1988;331:489-95.

16 Rubartelli P, Niccoli L, Verna E, et al. Stent implantation versus balloon angioplasty in chronic coronary occlusions: results from the GISSOC trial. F Am Coll Cardiol 1998;32: 90-6.

17 Antoniucci D, Santoro GM, Bolognese L, et al. A clinical trial comparing primary stenting of the infarct-related artery with optimal primary angioplasty for acute myocardial infarction. 7 Am Coll Cardiol 1998;31:1234-9.

18 Van Belle E, Bauters C, Hubert E. Restenosis rates in diabetic patients. A comparison of coronary stenting and balloon angioplasty in native coronary vessels. Circulation 1997;96:1454-60.

19 De Scheerder IK, Strauss BH, de Feyter PJ, et al. Stenting of venous bypass grafts: a new treatment modality for patients who are poor candidates for reintervention. Am Heart $\mathcal{f}$ 1992;123:1046-54.

20 Fenton SH, Fischman DL, Savage MP, et al. Long-term angiographic and clinical outcome after implantation of balloon-expand clinical outcome after implantation of vein grafts. Am $\mathcal{F}$ Cardiol 1994;74:1187-91.

21 Frimerman A, Rechavia E, Eigler N, et al. Long-term follow-up of a high risk cohort after stent implantation in saphenous vein grafts. F Am Coll Cardiol 1997;30:1277-83.

22 Heidland UE, Schoppmann D, Okasha NK, et al. Katheterinterventionelle Therapie stenosierter Bypassgefä $\beta \mathrm{e}-$ Ballonangioplastie. Dtsch Med Wochenschr 2000;125:20610

23 Maiello L, Colombo A, Gianrossi R, et al. Favourable results of treatment of narrowed saphenous vein grafts with of treatment of narrowed saphenous vein grafts with Palmaz-S $1212-16$.

24 Piana RN, Moscucci M, Cohen DJ, et al. Palmaz-Schatz stenting for treatment of focal vein graft stenosis: immediate results and long-term outcome. $\mathcal{F}$ Am Coll Cardiol 1994; 23:1296-304

25 Strumpf RK, Mehta SS, Ponder R, et al. Palmaz-Schatz stent implantation in stenosed saphenous vein grafts: clinical and angiographic follow-up. Am Heart fै 1992;123: 1329-36.

26 Wong SC, Baim DS, Schatz RA, et al. Immediate results and late outcomes after stent implantation in saphenous vein graft lesions: the Multicenter US Palmaz-Schatz stent experience. $\mathcal{F}$ Am Coll Cardiol 1995;26:704-12.

27 Savage MP, Douglas JS, Fischman DL, et al. Stent placement compared with balloon angioplasty for obstructed coronary bypass grafts. N Engl F Med 1997;337: $740-7$.

28 Bauters C, Hubert E, Prat A, et al. Predictors of restenosis after coronary stent implantation. $\mathcal{F}$ Am Coll Cardiol 1998; 31:1291-8.

29 Braunwald E. Unstable angina: a classification. Circulation 1989;80:410-14.

30 Elezi S, Kastrati A, Pache J, et al. Diabetes mellitus and the clinical and angiographic outcome after coronary stent placement. F Am Coll Cardiol 1998;32:1866-73.

31 Carrozza JP, Kuntz RE, Fishman RF, et al. Restenosis after arterial injury caused by coronary stenting in patients with diabetes mellitus. Ann Intern Med 1993;118:344-9.

32 Mehran, R, Mintz GS, Bucher TA. Aorto-ostial instent restenosis: mechanisms, treatment and results. A serial quantitative angiographic and intravascular ultrasound study [abstract]. Circulation 1996;94(suppl I):I-200.

33 Kasaoka S, Tobis JM, Akiyama T, et al. Angiographic and intravascular ultrasound predictors of in-stent restenosis. $\mathcal{F}$ Am Coll Cardiol 1998;32:1630-5.

34 Elezi S, Kastrati A, Neumann FJ, et al. Vessel size and longterm outcome after coronary stent placement. Circulation 1998;98:1875-80 